IZA DP No. 8841

The Impact of Refugee Crises on Host Labor Markets: The Case of the Syrian Refugee Crisis in Turkey

Yusuf Emre Akgündüz

Marcel van den Berg

Wolter Hassink

February 2015 


\title{
The Impact of Refugee Crises on Host Labor Markets: The Case of the Syrian Refugee Crisis in Turkey
}

\author{
Yusuf Emre Akgündüz \\ Utrecht University
}

Marcel van den Berg

Statistics Netherlands

Wolter Hassink

Utrecht University

and IZA

Discussion Paper No. 8841

February 2015

IZA

P.O. Box 7240

53072 Bonn

Germany

Phone: +49-228-3894-0

Fax: +49-228-3894-180

E-mail: iza@iza.org

\begin{abstract}
Any opinions expressed here are those of the author(s) and not those of IZA. Research published in this series may include views on policy, but the institute itself takes no institutional policy positions. The IZA research network is committed to the IZA Guiding Principles of Research Integrity.

The Institute for the Study of Labor (IZA) in Bonn is a local and virtual international research center and a place of communication between science, politics and business. IZA is an independent nonprofit organization supported by Deutsche Post Foundation. The center is associated with the University of Bonn and offers a stimulating research environment through its international network, workshops and conferences, data service, project support, research visits and doctoral program. IZA engages in (i) original and internationally competitive research in all fields of labor economics, (ii) development of policy concepts, and (iii) dissemination of research results and concepts to the interested public.
\end{abstract}

IZA Discussion Papers often represent preliminary work and are circulated to encourage discussion. Citation of such a paper should account for its provisional character. A revised version may be available directly from the author. 
IZA Discussion Paper No. 8841

February 2015

\section{ABSTRACT}

\section{The Impact of Refugee Crises on Host Labor Markets: The Case of the Syrian Refugee Crisis in Turkey*}

The civil war in Syria has culminated into major refugee crises in its neighboring countries. By the end of 2013 more than half a million people were seeking shelter in cities and refugee camps in Turkey. We analyze how the Syrian refugee influx in Turkey has affected food and housing prices, employment rates and internal migration patterns in regions of Turkey where refugees are being accommodated. Refugee camps are geographically concentrated near the Syrian border, which enables us to employ the rest of regional Turkey as control group with a difference-in-difference approach to analyze the impact on local economies. Our findings suggest that housing and to a lesser degree food prices increased, but employment rates of natives in various skill groups are largely unaffected. Incumbent natives appear to be staying put considering the limited migration out of the region, but there is a significant decline in internal migration into regions hosting refugees. Nevertheless, the decline in internal in-migration is less than a tenth of the refugee influx, implying that there is little evidence of refugees crowding out natives in local labor markets.

JEL Classification: F22, J61, R23

Keywords: refugees, employment, migration, inflation, regional economy, difference-in-difference

Corresponding author:

Wolter Hassink

Utrecht University

Utrecht University School of Economics

Kriekenpitplein 21-22

3584 EC, Utrecht

The Netherlands

E-mail:w.h.j.hassink@uu.nl

* The content of this publication does not reflect the official opinion of Statistics Netherlands. Responsibility for the information and views expressed in the paper lies entirely with the authors. 


\section{Introduction}

The Syrian Civil War that began in 2011 has had an enormous human cost. The casualty toll has risen to over 150,000 deaths in 2013. The United Nations puts the number of people who have fled their homes at 9 million. While 6.5 million of these refugees are internally displaced in Syria, 2.5 million have become refugees in Syria's neighboring countries: Turkey, Lebanon, Jordan and Iraq. Accommodating this many refugees, whose return dates are uncertain at best, is bound to not only put a strain on host countries' public finances, but affect local economies as well. In Turkey, refugees started arriving in May 2011. At first, numbers of arriving refugees were relatively small at about 7,600 in November 2011 according to UNCHR statistics. The situation had reached crisis proportions by the end of 2012 when the total number of registered refugees in Turkey was approximately 135,000. The flood of refugees continued and reached 500,000 by the end of 2013. Refugee crises of this extent constitute some of the sharper immigration shocks in recent history and it is crucial to understand to what extent such refugee influxes impact host countries'.

The impact of immigration on the labor market for natives has long been difficult to pin down for economists. The standard static model would suggest that migration increases supply and thus competition in the local labor market, leading to lower employment and wages of natives. However, most studies find little or no effects from immigration on the labor market position of natives (Dustmann, Glitz, and Frattini, 2008; Borjas, 2013). A number of explanations have been offered for the lack of labor market effects of immigration at the local level. One potential cause for the missing impact is suggested by Borjas (2006) who argues that immigration in a particular area leads to a lower internal migration to that area from the rest of the country, dampening the effect on employment and wages. Consequently, constructing the counterfactual for areas facing immigration is difficult since regions that could serve as control group may be at the receiving end of internal migration. Nevertheless, the size (or even the presence) of the internal migration effect is contested by Card (2005) who argues that there is little evidence of immigrants (to US) harming employment opportunities of natives. A further issue that is usually outside the scope of the literature on the labor market is the potential impact of large scale immigration on local consumer markets. A sudden shock in migration leading to higher demand and rising food, housing and other basic goods' prices, as Alix-Garcia and Saah (2010) suggests, may partly explain the lacking impact on wages. Increased prices in food and housing would in fact lower real wages for households spending a large portion of their income on basic goods, even if their nominal wages or wages 
adjusted for general inflation remains constant.

Studies employing quasi-experimental designs or exogenous shocks to investigate labor market outcomes are relatively few. An early study concerned the Miami boatlift in the early 1980s by Card (1990) who find little effects on wages and employment from an incoming migration wave. Hunt (1992) and Carrington and De Lima (1996) study the impact of the repatriates from the African colonies to France and Portugal respectively and find negative effects on employment and wages. A potential problem of these studies is that repatriates are able to choose to settle in areas with better economic prospects, leading to the underestimation of employment and wage effects. Carrington and De Lima (1996) employed France and Spain as control groups while studying the situation in Portugal, but the common trend assumption between countries is more difficult to hold up due to the concurrent economic downturn in Europe during the mid-1970s. A recent example of a quasi-experiment rooted in political turmoil is that of Glitz (2012) who exploits German migration regulations in 1989 to identify the effects of Germans in Eastern Europe returning to Germany. Glitz (2012) overcomes many of the problems in previous analysis by using migration regulations hinging on proximity to family members and finds small negative effects on wages and internal migration. With the exception of Card (1990), the reviewed literature on the impact of migration of labor market outcomes using quasi-experimental techniques is informative regarding the impact of returning co-ethnics or repatriates from colonies on the local labor market, but these incoming migrants tend to be relatively high skilled or at least have the required knowledge of the language to adapt easily to their living environment. However, the focal point of of debates in Europe largely concerns migration of poor and largely unskilled immigrants and refugees driven away from their home country by war and civil unrest to more developed countries.

Analysis of geographical correlations between immigration flows and labor market outcomes are usually suspected of underestimation of effects. If immigrants choose areas with better prospects, the expected negative effect on native employment will be underestimated. The most obvious solution is to exploit exogenous shocks leading to large scale immigration, but they too can be difficult to analyze. If there are no measures effective limiting immigrants' location choices within the host country, it will be difficult to construct a control group. Geographical constraints on the location of the refugee camps and the dramatic speed at which refugees started crossing the Turkish border allow us to circumvent many of the empirical identification and exogeneity issues discussed by Dustmann, Glitz, and Frattini (2008). The Syrian refugees' destination in Turkey seems to be limited geographically to the location of the refugee camps in the border region and the size 
of the inflow is large enough to allow for the estimation of the effects on employment using regional data in a simple difference-in-difference framework. Since we have data on local employment and internal migration rates, the effects on incumbent natives and new entrants can be thought of as being analyzed separately.

Large scale refugee influxes generally occur in areas where both the country people are fleeing from and the country taking up refugees are characterized by low levels of development such as the refugee crisis in Tanzania due to people fleeing from Rwanda in the 1990s (Baez, 2011). As such, the resulting labor markets are likely to be highly underdeveloped and regionally constrained rendering it impossible to assess the impact of the refugee influx. The Syrian civil war has created a situation where refugees are fleeing to a more developed country with a different culture and language, where they are generally lacking the host country related skills (e.g. language) and are not selected or self-selected into migration which is commonly the case in international migration McKenzie and Rapoport (2010). A further advantage of employing a refugee crisis instead of conventional migration patterns to estimate the effects on local labor markets is the strict division between natives and refugees in official statistics. Since Syrian refugees are not counted in official statistics and do not have legal residence or citizenship, official statistics are representative for the incumbent native population. In addition, we analyze internal migration patterns, which might be particularly informative with respect to the behavior of new entrants on local labor markets from elsewhere within the country. The impact on food and housing prices serves as an informal test of the validity of using the Syrian refugee crisis as an external shock large enough to affect the local economies.

Our results indicate that the refugee inflows have increased food prices, and to a lesser extent prices of housing in regions hosting them. We also analyzed inflation in hotel and restaurant prices, where there do not appear to be any effects, which is consistent with the idea that the refugees increase demand mostly in basic survival goods. Price effects are theoretically more straightforward than employment and internal migration effects. Even if refugees are employed in food and housing sectors in disproportionate numbers and lower production costs, the immediate effect of the refugee inflows is likely to be an increase in demand and therefore prices of survival goods.

The key finding of our analysis is that employment appears to be unaffected by the inflow of Syrian refugees into Turkish regions bordering Syria. The lack of effects on employment is partly explained by the negative effect on net migration. However, the impact on net migration is explained more by the decrease in in-migration than an increase in out-migration as may have been expected. That is, fewer Turks move to the main hosting regions, 
but native Turks moving out of the hosting regions to unaffected parts of Turkey remains unaffected. The refugee crisis thus seems to have crowded out internal migration to areas hosting refugee camps. The main narrative emerging from our analysis thus does not suggest considerable labor market effects from the refugee crisis on natives, but it may lead to concern for the welfare of lower income groups considering the rise in food and housing prices.

The remainder of the paper is organized as follows. Section 2 provides a brief description of the legal and social status of the Syrian refugees and the development of their situation. Section 3 discusses the framework and the empirical methodology. Section 4 introduces the data employed in the analysis. Section 5 presents provides the main results and is followed by the robustness tests shown in section 6 . Section 7 concludes.

\section{Syrian refugees in Turkey}

In November 2011, responding to the civil war reaching the northern areas of Syria, approximately 7,000 refugees crossed the Turkish border. By the end of 2013, Turkey was hosting approximately 500,000 refugees, the third highest number after Lebanon and Jordan. Officially, the Turkish government did not recognize the Syrian refugees as asylum seekers. In technical terms the refugees were being treated as guests (Özden, 2013). This has two important implications. First, they cannot apply for asylum in a third country. This limits the opportunities of migrating to other countries. Second, unlike the refugee status, the guest status implies that refugees can be relocated by the Turkish government without any legal process. To alleviate the conditions of the Syrian refugees and to limit uncertainty, the government enacted a temporary protection policy that ensures an open border between Turkey and Syria and that promises no forced exits. The focus of our analysis of the treatment effect is on the years 2012 and 2013. At this point, it is difficult to stress the importance of monitoring longer term effects as more data become available as an avenue for further research. Instability in the region has reached new heights and the increase of unrest in northern Syria and Iraq along the Turkish border in 2014 has had profound effects on neighboring regions and important trade partners southeastern Turkey and Iraq. As such, it might be difficult to maintain the common trend assumption within a difference-in-difference model in later years if instability rises further.

The guest status of the Syrian refugees is important to keep in mind in our empirical analysis. Many papers analyzing the impact of migration on labor market outcomes suffer from what Friedberg and Hunt (1995) call 
the 'composition problem'. If employment levels among migrants are lower than among incumbents, receiving more migrants in a region will lower the employment rate, independent of any effects on the incumbents (natives) participating on the labor market. As such, interpreting lower employment rates as the effect of migration on natives becomes questionable. Since Syrian refugees do not have residential or citizenship status, they are not counted in official provincial statistics on employment or internal migration. As such, analyzing the effects of the refugee influx in Southern Turkey will provide us with net employment effects on natives and other migrants in the area, independent of employment rates among refugees.

The United Nations High Commission of Refugees (UNCHR) reports that about half of the registered refugees were living in camps at the end of 2013 while the other half were living in urban areas mostly close to the camps. Figure 1 shows that most of the refugee camp locations are close to the border in the southeastern part of Turkey. This region of Turkey is characterized by relatively low population densities. Total population in the region hosting refugees is approximately 10 million. ${ }^{1}$ The arrival of 500,000 Syrians is thus likely to have noticeable consequences for the local economy. A small number of refugees has also relocated to the larger cities in the western parts of Turkey, such as Istanbul and Izmir. However, this mostly concerns those with relatives in metropolitan areas or those better equipped to settle elsewhere (Güçer, Karaca, and Dinçer, 2013).

While registration does not immediately translate into a work permit, Syrians are employed mainly informally as work permits are starting to be issued only slowly. There are no official numbers (nor reliable estimates) on how many refugees have entered the local labor market, but Syrians are reportedly employed mainly in low-skilled jobs in construction and service sectors (Dinçer, Federici, Ferris, Karaca, Kirişci, and Çarmıklı, 2013). The language barrier is likely to limit employment in high-skilled jobs.

\section{Theoretical framework and empirical strat- egy}

We study the effects of the Syrian refugee crisis in southeastern Turkey on three dimensions of the local economy, (1) the average price levels, food

\footnotetext{
${ }^{1}$ In terms of the NUTS-3 classification, refugee camps are located in the regions of Hatay (Antakya), Adana, Osmaniye, Kilis, Kahramanmaraş, Gaziantep, Şanlıurfa, Mardin, Adiyaman and Malatya. See http://en.wikipedia.org/wiki/NUTS_of_Turkey for an overview of the regional division of Turkey according to the NUTS-classification.
} 
Figure 1: Syrian refugee camps in Turkey (source: UNCHR)

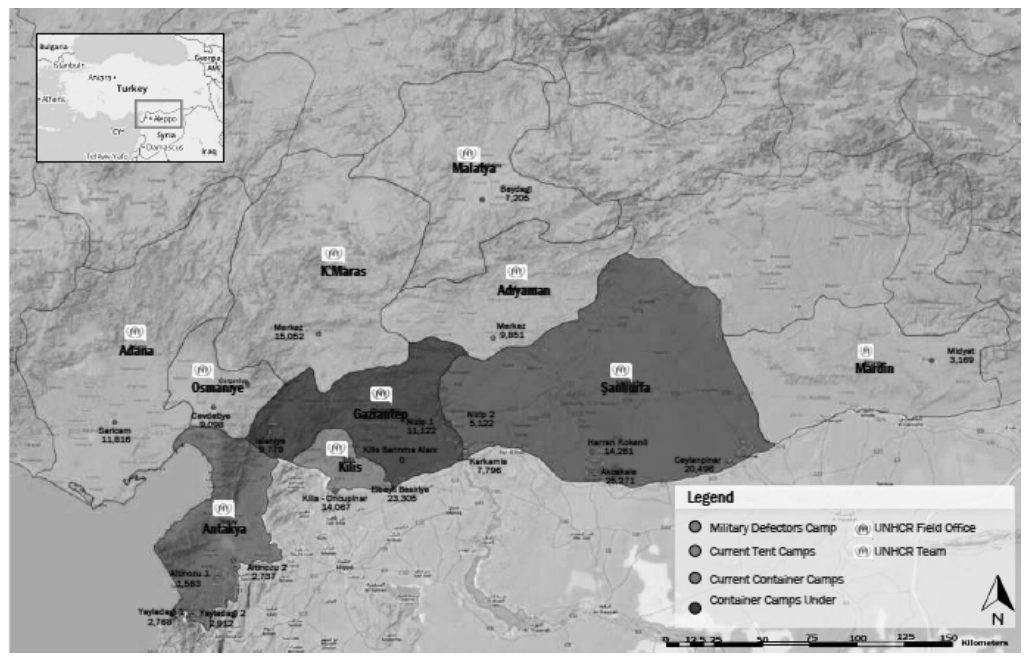

prices and housing prices, (2) unemployment rates (distinguishing between skill groups), and (3) internal migration (within Turkey) both in terms of inflows and outflows into the regions affected by the refugee crisis.

The impact of a considerable refugee influx on prices of necessity goods is a well-established concern in the literature on the effects of refugee inflows on local communities. Our analysis of the price response to the refugee crisis serves mostly as a robustness check of the impact of the refugee crisis on the local economy. Unless the local economy is free of any rigidities and fully integrated with other geographic markets without any barriers, a sudden increase in the demand for food and housing will induce an increase in the price level of these commodities. Alix-Garcia and Saah (2010) show that the refugee crisis in Rwanda caused an increase in food prices in Tanzania and that food aid can help dampen price level increases. Note that the study of Alix-Garcia and Saah (2010) concerns an analysis of food prices at the national level in Tanzania. Empirical research on intranational price level differences and its determinants is relatively scarce. However, in a more recent contribution Roos (2006) corroborates the narrative from the small body of existing literature by showing that regional price level differences in Germany are considerable and persistent. Roos (2006) identifies population size and wage levels to be key drivers of regional price level variation. This illustrates the relevance of considering the impact of the refugee influx on regional price levels in our analysis.

In addition, since refugees are unlikely to have sufficient spending power to exert any pressure on the prices of more luxury goods, the hospitality sector should be relatively unaffected due to the refugee influx. The analysis 
of the impact of the refugee inflows on the hospitality sector thus serves as a test of the internal consistency of our results concerning food and housing prices.

The local labor market in each Turkish province can be considered to be consisting of three groups: Syrian refugees, native incumbents and new entrants from other provinces of Turkey. While the price response to refugee inflows would also affect the welfare of incumbents, our primary interest is whether or not their employment is affected. Expected negative effects on native employment do not seem to materialize in the literature but the size of the effects may be dependent on the characteristics of migrants (Chiswick, 1989). If the skill composition of migrants is the same as natives, the effects would be null in a constant elasticity of substitution model where capital and labor inputs are separable (DiNardo and Card, 2000). The effects are thus only expected in cases where the migrant population has a different skill composition compared to the native population as in the case of Katrina evacuees to Houston (De Silva, McComb, Moh, Schiller, and Vargas, 2010). In case of the Syrian refugees in Turkey, their informal employment might even make them more attractive for employers attempting to avoid paying social security taxes on incumbents. This might lead us to expect stronger negative effects since refugees may be more attractive than natives in lowskill sectors where informal employment is possible. Conversely, since Syrian refugees are unlikely to have the necessary language skills (Turkish), they are unlikely to affect medium and high-skill employment.

Entrants on local labor markets moving to the area from other parts of Turkey may also be affected by the influx of refugees. Should finding a job become more difficult or should there be any other negative welfare effect of living in a province hosting Syrian refugees then internal migration to these provinces may decline. We empirically investigate the effect of hosting refugees on entrants by distinguishing between entry, exit and net migration rates of affected provinces. A possible lack of effects on employment rates and wages could be (at least partly) explained by a negative effect that immigration seems to have on internal migration. Borjas (2006) finds that non-native migration into specific regions leads to simultaneous higher exit rates and lower entry rates into these regions by natives. This finding is echoed by Pischke and Velling (1997) regarding Germany. As such, the effects on employment may be more difficult to identify since they may affect a larger area than merely the provinces in which refugees are located. As an informal test of this hypothesis, we estimate employment effects at both regional and provincial levels. 


$$
\begin{array}{r}
\pi_{i t}=a+\rho I_{i t}+T_{t}+R_{i}+e_{i t} \quad i=1, \ldots, 26 \quad t=1, \ldots, 10 \\
S_{i t}=a+\rho I_{i t}+T_{t}+R_{i}+e_{i t} \quad i=1, \ldots, 26 \quad t=1, \ldots, 10 \\
E_{j t}=a+\rho I_{j t}+T_{t}+C_{j}+e_{j t} \quad j=1, \ldots, 81 \quad t=1,2,3,4,5 \\
\frac{M_{j t}}{P_{j t-1}}=a+\rho I_{j t}+T_{t}+C_{j}+e_{j t} \quad j=1, \ldots, 81 \quad t=1,2,3,4,5
\end{array}
$$

We fit a linear difference-in-difference model with fixed effects for migration and employment outcomes. Three inflation outcomes, $\pi_{i t}$, are analyzed at the level of 26 provinces: food, housing and hospitality sectors' inflation. To analyze the effects on employment, we use five outcomes: employment rates at the level of 81 provinces and 26 regions and employment rates for high, medium and low educated persons at the level of 26 regions, $S_{i t}$. Three outcomes are used for internal migration in 81 provinces: entry rate, exit rate and the net migration rate. The estimated models are shown by equations 1 to 4. All models are estimated with both year, $T_{t}$, and region fixed effects. Depending on whether the model is based on data from region or province levels, 80 province fixed effects, $C_{j}$, and 25 region effects $R_{i}$ are included. The main variable of interest is treatment effect $I$, which is either a binary variable indicating the presence of refugees or the number of refugees or the number of refugees in the area transformed using the inverse sine function. The inverse sine function is used to normalize variables such as wealth where log transformation is inappropriate due to a large number of observations with the value zero (Carroll, Dynan, and Krane, 2003). All regressions use standard errors clustered at the region or province level to control for area specific shocks.

For every dimension under investigation, we fit a secondary model, allowing us to control for region-specific factors that may vary over time. Our main concern regards international trade patterns of regions bordering Syria. If a collapse of exports to and imports from Syria has a larger impact on the local economy of the Turkish regions bordering Syria, the common trend assumption may be violated especially in the analysis of determinants of regional prices. We add control variables for total imports and exports from each region (or province) in a secondary model to control for any impact of trade shocks on the dependent variable of interest. ${ }^{2}$ Several further control variables are added to each model. In the regression model concerning inflation, we include the population of the region and the unemployment rate.

\footnotetext{
${ }^{2}$ As a further test we estimated equation 1 with total imports and exports as dependent variables. The results show no significant impact from the refugee influx on trade.
} 
We use the lag of the population in our regression model on migration, since the current population is partly determined by inter-country migration. We also employ the unemployment rate as an additional control variable in this model. We only control for population in our additional model for employment. Adding these control variables to the regression models generally do not significantly change the estimation results.

A common concern in the literature concerning natural experiments is the size of the standard errors. We follow the suggestion of Bertrand, Duflo, and Mullainathan (2004) and cluster the standard errors at the provincial and regional level. However, in our regressions at the NUTS-2 regional level (26 regions in total), the number of clusters may be too low. A common rule of thumb is a minimum of 50 clusters in order to avoid underestimation of the standard errors and type I errors. In regressions clustered at the NUTS-2 level, we test the reliability of the standard errors by using the bootstrapbased method of Cameron, Gelbach, and Miller (2008) (henceforth CGM) designed specifically to rule out type I errors ('false positives') in regressions with numbers of clusters between 5 and 30 .

\section{Data}

Since the number of refugees was still relatively small in 2011, we consider 2012 the first year of 'treatment' in our empirical analysis. Treatment in our analysis is defined as Syrian refugees fleeing from Syria to specific Turkish regions. Data on the numbers of refugees in southeastern Turkey are drawn from the December 2012 and 2013 reports of the UNCHR on Syrian refugees in Turkey (?). The number of Syrian refugees in Turkey in 2012 only concern refugees in camps while the 2013 numbers also include refugees in urban areas. The number of refugees outside camps was still relatively low in 2012; 40,000-60,000. In addition, there is no exact information regarding the regions in which they were located. The total number of refugees in 2012 amounts to about 200,000, while in 2013 this number had increased to about 560,000 . The UNHCR estimates the number of refugees outside camps at the provincial level. In 2013, about half the refugees was located outside camps.

In 2012 three NUTS-2 level regions constituted the main area providing Syrian refugees with shelter. In 2013, this number has increased to six regions. The total number of refugees corresponded to 3.4 percent of the total population in 2012 and 5 percent in 2013. Numbers of refugees staying in southeastern Turkey along with incumbent population sizes and local GRP-figures are provided in table 1. 
Table 1: Number of refugees, population size and GRP

\begin{tabular}{llcccc}
\hline NUTS-2 & NUTS-3 (province) & \multicolumn{2}{c}{ number of refugees } & population & GRP \\
\cline { 3 - 4 } (region) & & 2012 & 2013 & 2013 & 2012 \\
\hline Adana & Adana, Mersin & - & 16,666 & 2,747 & 7,232 \\
Hatay & Hatay, Kahramanmaraş, Osmaniye & 38,129 & 132,490 & 2,218 & 5,904 \\
Malatya & Malatya, Elaziğ, Bingöl, Tunceli & - & 7,205 & 1249 & 5,820 \\
Gaziantep & Gaziantep, Adıyaman, Kilis & 48,753 & 219,250 & 1,686 & 4,952 \\
Sanlıurfa & Sanlıurfa, Diyarbakır & 61,112 & 135,357 & 2,127 & 4,282 \\
Mardin & Mardin, Batman, Sirnak, Siirt & - & 40,965 & 1,279 & 4,689 \\
\hline
\end{tabular}

We begin our analysis by studying the effects of the refugee influx on inflation. The focus is primarily on the inflation of two commodities that are likely to be characterized by the existence of local markets where the sudden refugee influx will put a strain on demand: food and housing. In addition, inflation in hospitality sectors is included in the analysis as a test of the internal consistency of our findings. Estimates on inflation are obtained by taking the average of monthly inflation rates of a given year. Monthly averages seem more reliable than subtracting price levels in December from price levels in December of the previous year to construct annual inflation rates since there may be seasonal price adjustments unique to individual years. As a robustness test, we also used monthly inflation data. Data concerning inflation rates are provided by Turkish Statistics (?) and is available at the level of NUTS-2 regions for the years 2004 to 2013, $N=260$.

Turkey is officially divided into 81 provinces, each of which has its own large municipality. TUIK provides data concerning internal migration at the level of 81 provinces (NUTS-3 regions) between 2008 and 2013 resulting in a total of 486 observations. We look at three dimensions: entry, exit and net migration. In line with Borjas (2006) and much of the migration literature, these variables are converted into rates by dividing them with the native population in the previous year, $M_{t} / N_{t-1}$. Since these values concern internal migration at the national level, the mean of each year equals zero.

Employment data is available at both the provincial and the regional level. There is no set limit on whether a single labor market consists of a province or the entire region as the size of the labor market will depend largely on the mobility of employees. In addition, the employment data at the regional data include a division by skill level. Three education levels are distinguished: (1) individuals without a high school degree are defined as poorly educated, (2) individuals with a high school degree as intermediately educated and (3) individuals with vocational training or higher as highly educated. In addition, a separate, fourth, group is identified for individuals 
who do not know how to read or write but there are too few individuals in that category for most regions to include in the analysis.

In table 2 we show the summary statistics for inflation, employment and internal migration serving as the input for our analysis. The years 2012 and 2013 are considered the treatment years. Average values are presented for the 20 regions that do not host any refugee camps (the control group) and the six regions that ultimately host refugees (treatment group). We separate between the period before and after treatment. At the provincial level, ten provinces host refugee camps in 2013 and 71 do not. The intertemporal developments of the outcome variables of interest are plotted in Figures A1, A3 and A2 in the appendix. The common trend assumption for the difference-indifference model seems satisfied visually for most variables since the average values for control group and treatment group generally move in the same direction.

Table 2: Inflation and employment in Turkey before and after the refugee crisis

\begin{tabular}{|c|c|c|c|c|c|c|c|}
\hline & \multicolumn{3}{|c|}{ pre-2012 } & \multicolumn{3}{|c|}{ post-2012 } & \multirow[b]{2}{*}{ dif-in-dif } \\
\hline & $\begin{array}{l}\text { rest of Turkey } \\
\text { (control) }\end{array}$ & $\begin{array}{l}\text { southeast } \\
\text { (treatment) }\end{array}$ & difference & $\begin{array}{l}\text { rest of Turkey } \\
\text { (control) }\end{array}$ & $\begin{array}{c}\text { southeast } \\
\text { (treatment) }\end{array}$ & difference & \\
\hline \multicolumn{8}{|l|}{ inflation } \\
\hline hospitality $(N=234)$ & 11.1261 & 11.9376 & -0.8115 & 8.826 & 8.5824 & 0.2436 & 1.0551 \\
\hline food $(N=260)$ & 9.1295 & 8.8973 & 0.2322 & 8.57 & 9.02 & -0.45 & 0.682 \\
\hline housing $(N=260)$ & 10.5406 & 10.8783 & -0.3378 & 9.5455 & 10.3808 & -0.8353 & 0.5155 \\
\hline \multicolumn{8}{|l|}{ employment (NUTS-3) } \\
\hline employment rate $(N=486)$ & 44.9993 & 37.365 & 7.6343 & 47.1169 & 39.5 & 7.6169 & 0.0174 \\
\hline unemployment rate $(N=486)$ & 9.9472 & 14.3475 & -4.4003 & 8.0887 & 11.66 & -3.5713 & -0.829 \\
\hline \multicolumn{8}{|l|}{ employment (NUTS-2) } \\
\hline low education $(N=260)$ & 51.0455 & 45.4686 & 5.5768 & 54.4816 & 47.081 & 7.4006 & -1.8238 \\
\hline medium education $(N=260)$ & 63.4815 & 59.9102 & 3.5713 & 63.7196 & 59.0131 & 4.7064 & -1.1351 \\
\hline high education $(N=260)$ & 77.0806 & 76.4646 & 0.616 & 77.6739 & 77.0535 & 0.6205 & -0.0045 \\
\hline \multicolumn{8}{|l|}{ migration (rates x1000) } \\
\hline entry rate $(N=486)$ & 36.8981 & 27.3865 & 9.5117 & 40.4692 & 26.9338 & 13.5354 & -4.0237 \\
\hline exit rate $(N=486)$ & 41.3477 & 33.1 & 8.2477 & 41.0899 & 33.5019 & 7.588 & 0.6597 \\
\hline net migration rate $(N=486)$ & -4.4498 & -5.7136 & 1.264 & -0.6207 & -6.5681 & 5.9474 & -4.6834 \\
\hline
\end{tabular}

\section{Results}

\subsection{Inflation}

Table 3 shows the effects of the refugee crisis on inflation of hospitality, food and housing prices. The refugee crisis appears to have caused an increase in food and housing prices. The coefficients for inflation of food prices are particularly significant while the significance of the effect on housing price 
level increases varies across specifications. As discussed earlier, we test the effects on inflation of hospitality price levels as a check on the consistency of the results, since there is little reason to assume that the influx of Syrian refugees raises price levels of luxury goods. The effect of the refugee influx on price levels hospitality sectors are statistically insignificant. The results are in line with the expectation that local demand by refugees concentrates in necessity goods.

Table 3: Impact of the refugee influx on local inflation rates by commodity at the regional level

\begin{tabular}{|c|c|c|c|c|c|c|}
\hline & \multicolumn{2}{|c|}{ hospitality } & \multicolumn{2}{|c|}{ food } & \multicolumn{2}{|c|}{ housing } \\
\hline & $(1)$ & $(2)$ & (1) & $(2)$ & $(1)$ & $(2)$ \\
\hline \multicolumn{7}{|c|}{ dependent variable: dummy variable indicating refugee presence } \\
\hline treatment effect & -1.3258 & -0.8723 & 0.8200 & 0.8057 & 0.6937 & 1.2806 \\
\hline clustered SE & $(1.004)$ & $(1.066)$ & $(0.255)^{* * *}$ & $(0.289)^{* * *}$ & $(0.464)$ & $(0.507)^{* *}$ \\
\hline CGM SE & $(1.050)$ & $(1.273)$ & $(0.262)^{* * *}$ & $(0.290)^{* * *}$ & $(0.532)$ & $(0.578)^{* *}$ \\
\hline \multicolumn{7}{|c|}{ treatment variable: \# of refugees hosted in the region } \\
\hline treatment effect & -0.2550 & -0.1460 & 0.2046 & 0.2039 & 0.1488 & 0.2867 \\
\hline clustered SE & $(0.211)$ & $(0.235)$ & $(0.066)^{* * *}$ & $(0.071)^{* * *}$ & $(0.083)^{*}$ & $(0.082)^{* * *}$ \\
\hline CGM SE & $(0.241)$ & $(0.258)$ & $(0.079)^{* * *}$ & $(0.087)^{* *}$ & $(0.094)$ & $(0.092)^{* * *}$ \\
\hline no. of obs. & 234 & 234 & 260 & 260 & 234 & 234 \\
\hline no. of regions & 26 & 26 & 26 & 26 & 26 & 26 \\
\hline
\end{tabular}

The results show a considerable difference between the robust and clustered standard errors. ${ }^{3}$ Robust standard errors are considerably larger in most cases. To test whether this is due to the small number of clusters, we employ the bootstrapping technique suggested by Cameron, Gelbach, and Miller (2008). This yields satisfying results, even in cases with very few $(N=4)$ clusters. The resulting standard errors are slightly larger than the standard clustered errors but the significance levels change only slightly.

The number of Syrian refugees in 2012 was approximately 3.4 percent of the population in the three regions with refugee camps while the corresponding number was 5 percent for the six regions in 2013. The coefficients enable us to estimate that the an inflow of refugees equivalent to 1 percent

\footnotetext{
${ }^{3}$ Robust standard errors are not reported in the table.
} 
of the population would increase food inflation by 0.2 percentage points or approximately 2.2 percent since the average food inflation rate in the region is around $9 \%$. In economic terms, these effects are not particularly large. The effects are slightly larger for housing inflation but the coefficients are not consistently significant in that case. Nevertheless, the results show that the impact of the refugee inflow is consistent with the theoretical framework where higher demand leads to higher inflation.

We performed two further tests on the robustness of the inflation results. First, monthly inflation data was used to estimate the effects of the refugee crisis on food and housing prices. The results are similar to model 1 presented in table 3 with significant effects on food prices and insignificant effects on housing prices. Model 2 cannot be estimated with monthly inflation since many of the controls are reported only yearly. Second, we used a model with a lagged inflation to estimate the effects as found in (Ball and Sheridan, 2004; Mishkin and Schmidt-Hebbel, 2007) since inflation may be affected strongly by shocks in previous year's inflation. Ideally, both region effects and lag of prices should be controlled for in the regressions presented in table 3, but this leads to a well known endogeneity problem (Nickell, 1981). Instrumental variables methods have been suggested to be able to estimate a fixed effects model with lagged dependent variables but Angrist and Pischke (2008) find these assumptions to be quite strict and instead suggest fitting a model with both fixed effects and lagged dependent variables to test the robustness of the estimates. The two models are expected to give boundaries on the true effect, with fixed effects models the upper and the lagged dependent variable models the lower bound. The inflation models with lagged dependent variables indeed show smaller effects for both food and housing prices. While the effects on food prices remain significant with a coefficient of -0.76 for the model without controls instead of the -0.82 reported in table 3 , effects on housing prices become insignificant.

\subsection{Migration}

Table 4 presents the regression model results with internal migration as our dependent variable of interest. The dependent variables are divided by the lag of the population following Borjas (2006), which results in the first year of data inevitably getting dropped from the analysis. However, the results are similar if we simply use the numbers of migrants, in order to include 2008-values. The results show highly significant effects on the entry rate, which seem to drive the net migration rates. The effects on exit rates are small and insignificant, indicating that incumbent inhabitants do not seem 
Table 4: Impact of the refugee influx on internal migration at the provincial level

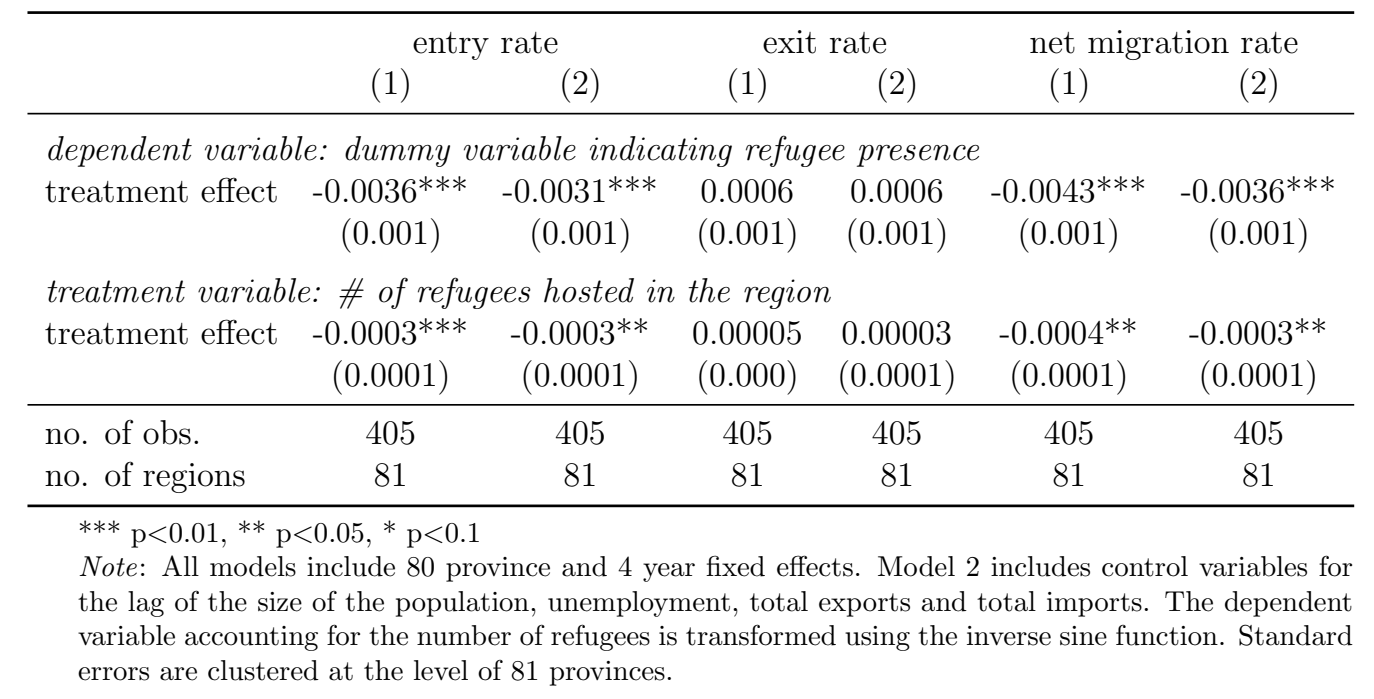

to may away because of the refugee influx in the region.

Since exit rates are largely unaffected by the refugee inflows, it appears that native incumbents on the labor market are largely staying put. However, potential new entrants into the region seem to be staying away due to the inflow of refugees. Multiple explanations could be provided for the behavior of internal migrants. Competition on the labor market could be perceived to be higher due to the influx of Syrian refugees trying to find employment in Turkey. Furthermore, increasing food and housing prices that we show to have increased or changes in the composition of the population that Card, Dustmann, and Preston (2012) argue lead to a negative sentiment from the natives for immigrants may be resulting in lower entry rates into the region.

\subsection{Employment}

The final dimension we consider in our empirical analysis is employment. In table 5, the results are presented for employment rates both at the regional and provincial level. In table 6 , the effect of the refugee influx on employment rates for different subsets by education level are shown. The coefficients consistently return the expected negative sign and but none are significant. In addition, the coefficients seem to be more negative for lower education levels. 
Table 5: Impact of the refugee influx on employment at the provincial and regional level

\begin{tabular}{|c|c|c|c|c|}
\hline & \multicolumn{2}{|c|}{ Employment (region) } & \multicolumn{2}{|c|}{ Employment (province) } \\
\hline \multicolumn{5}{|c|}{ dependent variable: dummy variable indicating refugee presence } \\
\hline treatment effect & $\begin{array}{c}0.2229 \\
(1.582)\end{array}$ & $\begin{array}{c}-0.4634 \\
(1.179)\end{array}$ & $\begin{array}{l}0.0724 \\
(0.889)\end{array}$ & $\begin{array}{l}0.0351 \\
(0.880)\end{array}$ \\
\hline \multicolumn{5}{|c|}{ dependent variable: \# of refugees hosted in the region } \\
\hline treatment effect & $\begin{array}{c}-0.0479 \\
(0.293)\end{array}$ & $\begin{array}{c}-0.0372 \\
(0.277)\end{array}$ & $\begin{array}{c}-0.0009 \\
(0.083)\end{array}$ & $\begin{array}{c}-0.0051 \\
(0.081)\end{array}$ \\
\hline no. of obs. & 260 & 260 & 486 & 486 \\
\hline
\end{tabular}

Note: All models include 25 region (80 province) and 9 (5) year fixed effects. Model 2 includes a control variable for population. The dependent variable accounting for the number of refugees is transformed using the inverse sine function. Standard errors are clustered at the level of 26 regions or 81 provinces.

Despite the large number of refugees entering Turkey in the last two years, we find no impact on employment, which is a result in line with previous studies looking at employment effects of immigration (Card, 1990; Dustmann, Fabbri, and Preston, 2005). A possible explanation for this finding is that the potential employment effects may be (partly) offset by a slowdown of internal migration. However, the decrease in internal migration is only about 0.4 percent of the population while the number of refugees arriving amounts to about 5 percent. There thus seems to be considerable net population growth without a corresponding effect on employment rates. The most obvious explanation would be that Syrian refugees are generally unable to compete with native incumbents on the labor market. A more positive interpretation would be that firms located in regions hosting Syrian refugees are able to adjust the skill requirements of their labor demand to accommodate the increase in the supply of low skilled employees. Either way, there seems to be little reason for incumbent natives to not stay put. The data show regarding internal migration rates show that this is exactly what people seem to be doing. 
Table 6: Impact of the refugee influx on employment at the regional level for different skill groups

\begin{tabular}{lcccccc}
\hline & \multicolumn{7}{c}{ low } & \multicolumn{2}{c}{ medium } & \multicolumn{2}{c}{ high } \\
& $(1)$ & $(2)$ & $(1)$ & $(2)$ & $(1)$ & $(2)$ \\
\hline dependent variable: dummy variable & indicating refugee & presence \\
treatment effect & -2.0135 & -1.1188 & -1.1125 & -0.3796 & -0.1917 & 0.2801 \\
clustered SE & $(2.183)$ & $(1.998)$ & $(2.042)$ & $(1.556)$ & $(1.707)$ & $(1.566)$ \\
CGM SE & $(2.071)$ & $(1.878)$ & $(3.905)$ & $(2.692)$ & $(1.555)$ & $(1.273)$ \\
treatment variable: \# of refugees hosted in the region & & \\
treatment effect & -0.5622 & -0.3653 & -0.3108 & -0.1479 & -0.0440 & 0.0634 \\
clustered SE & $(0.403)$ & $(0.358)$ & $(0.437)$ & $(0.328)$ & $(0.395)$ & $(0.363)$ \\
CGM SE & $(0.435)$ & $(0.339)$ & $(0.535)$ & $(0.418)$ & $(0.531)$ & $(0.326)$ \\
\hline no. of obs. & 260 & 260 & 260 & 260 & 260 & 260 \\
no. of regions & 26 & 26 & 26 & 26 & 26 & 26 \\
\hline
\end{tabular}

*** $\mathrm{p}<0.01,{ }^{* *} \mathrm{p}<0.05,{ }^{*} \mathrm{p}<0.1$

Note: All models include 25 region and 9 year fixed effects. Model 2 includes control variables for the size of the population, total imports and total exports. The dependent variable accounting for the number of refugees is transformed using the inverse sine function. Standard errors are clustered at the region level.

\section{Robustness tests}

In this section we provide the results of the placebo tests and results from analysis with alternative control groups. A fundamental and crucial assumption in our analysis is the assumption of a common trend among regions hosting refugees and the rest of Turkey. In column (1) of table 7, we present placebo tests for the baseline specification with a placebo treatment in the years 2010 and 2011. The years 2012 and 2013 are left out of the analysis.

In column (2) of table 7 another potential concern regarding the use of the entirety of Turkey as control group is addressed. An issue could be that a number of illegal refugees may have migrated to the larger cities of Turkey: Istanbul, Ankara and Izmir. In column (2) of table 7, observations from these three cities are excluded.

Furthermore, it could be argued that western Turkey is too different in terms of economic development to serve as an appropriate control group for southeastern Turkey where most of the refugee camps are located. In columns (3) and (4), western and a portion of central Turkey is excluded 
from the analysis. As such, there are 17 regions and 58 provinces left in the analysis at the region and province levels respectively. Column (3) shows the result of the placebo test when western Turkey is excluded and column (4) provides the treatment effects.

Table 7: Placebo tests and alternative control groups

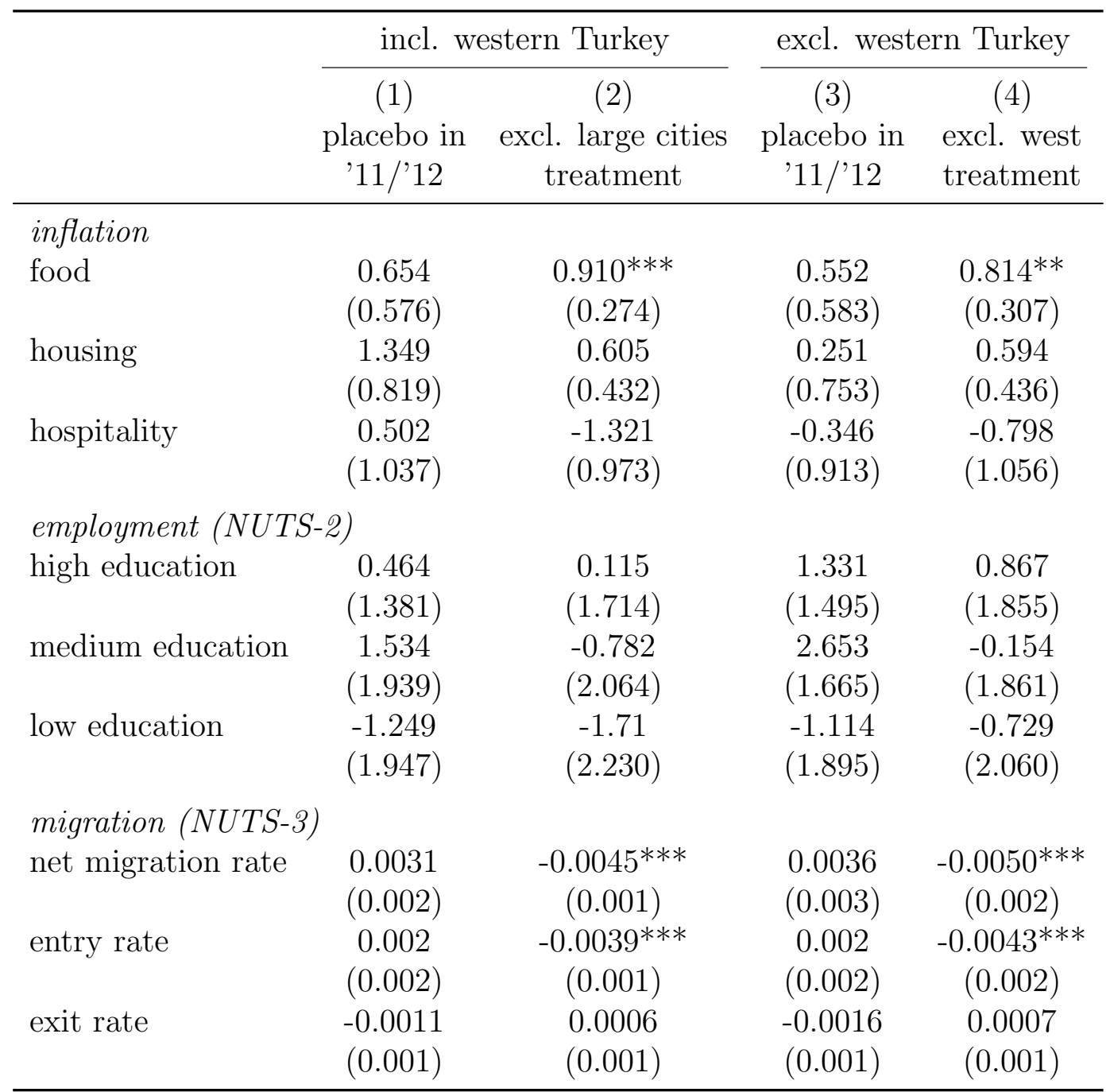

Note: All models include year and region/province fixed effects. Model 1 presents placebo tests of all regions of Turkey. Model 2 excludes regions of western Turkey.

In all cases shown in column (1) and (3), the impact of the placebo treatment appears insignificant. In both columns (2) and (4), the results are comparable to the baseline specifications where all Turkish regions serve as control group. If anything, the effects food prices seem to be more significant 
once the control groups exclude big cities or the western part of Turkey. Also the size of the effects on internal migration and inflation of prices are comparable. These simple robustness tests seem to indicate that the estimated effect sizes are consistent.

\section{Conclusion}

Despite the dramatic proportions of the refugee crisis in southeastern Turkey in 2012 and 2013, its impact on local commodity and labor markets do not seem to be considerable. The analysis in this study is done from the perspective of the natives of the regions hosting refugees who are the incumbents on the local labor market. We find no employment effects from the refugee inflows on natives' employment rates, is in line with the literature studying the employment effects of immigration. Perhaps the only disconcerting finding from the natives' perspective is the inflation of food and (to a lesser extent) housing prices. Price increases in these categories may disproportionately affect the lower income natives since it concerns essential survival goods. Nevertheless, migration flows show no impact of the refugee influx on exit rates from the region: natives appear to be staying put.

Turkish migrants contemplating moving to the regions hosting refugees from the rest of Turkey seem to be reconsidering their moving plans. Entry rates are significantly lower since the refugee crisis emerged while exit rates are unaltered. This may be due to competition on the labor markets between migrants of both Turkish and Syrian origin rather than between incumbent natives and refugees. However, we do not yet know how Syrian refugees are adapting to the Turkish labor markets as data on this matter are yet unavailable. Further research using more detailed information on consumption of both natives and refugees may be used to study the relationships between native and refugee communities.

The impact of immigration on employment may be at least partly offset by changing internal migration patterns that we also observe in Turkey. This is consistent with the main argument put forward by Borjas (2006). However the extent to which internal migration effects compensate for the refugee inflows seems limited since there are far more refugees arriving in the region than is compensated by decreasing net migration rates. Our results align more with Card (2005), who argues that immigration has little effects on the employment rates of natives. We find no effects from the refugee inflows on employment rates of natives regardless of the lower entry rates into the region by internal migrants and this result holds for both province and region levels and different skill groups. The case of Syrian refugees in Turkey is 
rather extreme compared to most of the migration literature. Despite lack of screening and self-selection, the mass movement of refugees from a different culture speaking a different language seems to have had no effect on the employment of natives.

\section{References}

AliX-Garcia, J., And D. SAAH (2010): "The effect of refugee inflows on host communities: Evidence from tanzania," The World Bank Economic Review, 24(1), 148-170.

Angrist, J. D., AND J.-S. PISChKe (2008): Mostly harmless econometrics: An empiricist's companion. Princeton university press.

BAEz, J. E. (2011): "Civil wars beyond their borders: The human capital and health consequences of hosting refugees," Journal of Development Economics, 96(2), 391-408.

BALl, L. M., AND N. SheridAn (2004): "Does inflation targeting matter?," in The Inflation-Targeting Debate, pp. 249-282. University of Chicago Press.

Bertrand, M., E. Duflo, and S. Mullainathan (2004): "How Much Should We Trust Differences-in-Differences Estimates?," Quarterly Journal of Economics, 119(1).

BorJas, G. J. (2006): "Native internal migration and the labor market impact of immigration," Journal of Human Resources, 41(2), 221-258.

(2013): "The analytics of the wage effect of immigration," IZA Journal of Migration, 2(1), 22.

Cameron, A. C., J. B. Gelbach, and D. L. Miller (2008): "Bootstrapbased improvements for inference with clustered errors," The Review of Economics and Statistics, 90(3), 414-427.

CARD, D. (1990): "The impact of the Mariel Boatlift on the Miami labor market," Industrial and Labor Relations Review, 43(2), 245-257.

(2005): "Is the new immigration really so bad?*," The Economic Journal, 115(507), F300-F323. 
Card, D., C. Dustmann, and I. Preston (2012): "Immigration, wages, and compositional amenities," Journal of the European Economic Association, 10(1), 78-119.

Carrington, W. J., and P. J. De Lima (1996): "The impact of 1970s repatriates from Africa on the Portuguese labor market," Industrial and Labor Relations Review, pp. 330-347.

Carroll, C. D., K. E. Dynan, and S. D. Krane (2003): "Unemployment risk and precautionary wealth: Evidence from households' balance sheets," Review of Economics and Statistics, 85(3), 586-604.

Chiswick, C. U. (1989): "The impact of immigration on the human capital of natives," Journal of Labor Economics, pp. 464-486.

De Silva, D. G., R. P. McComb, Y.-K. Moh, A. R. Schiller, and A. J. VArgas (2010): "The effect of migration on wages: evidence from a natural experiment," American Economic Review, pp. 321-326.

DiNardo, J., And D. CARd (2000): "Do Immigrant Inflows Lead to Native Outflows?," American Economic Review, 90(2), 360-367.

Dinçer, O. B., V. Federici, E. Ferris, S. Karaca, K. Kirişci, and E. Ö. ÇARMIKLI (2013): Turkey and Syrian Refugees: The Limits of Hospitality. International Strategic Research Organization (USAK).

Dustmann, C., F. Fabbri, and I. Preston (2005): "The Impact of Immigration on the British Labour Market," The Economic Journal, 115(507), F324-F341.

Dustmann, C., A. Glitz, and T. Frattini (2008): "The labour market impact of immigration," Oxford Review of Economic Policy, 24(3), 477494.

FriedberG, R. M., ANd J. Hunt (1995): "The impact of immigrants on host country wages, employment and growth," The Journal of Economic Perspectives, pp. 23-44.

GLITz, A. (2012): "The Labor Market Impact of Immigration: A QuasiExperiment Exploiting Immigrant Location Rules in Germany," Journal of Labor Economics, 30(1), pp. 175-213.

Güçer, M., S. Karaca, And O. B. DinçER (2013): The Struggle For Life Between Borders: Syrian Refugees. International Strategic Research Organization (USAK). 
Hunt, J. (1992): "The impact of the 1962 repatriates from Algeria on the French labor market," Industrial and Labor Relations Review, pp. 556-572.

McKenzie, D., And H. RApoport (2010): "Self-selection patterns in Mexico-US migration: the role of migration networks," The Review of Economics and Statistics, 92(4), 811-821.

Mishkin, F. S., and K. Schmidt-Hebbel (2007): "Does inflation targeting make a difference?," NBER Working Paper No. 12876, National Bureau of Economic Research.

NiCKELl, S. (1981): "Biases in dynamic models with fixed effects," Econometrica, pp. 1417-1426.

PischKe, J.-S., AND J. Velling (1997): "Employment effects of immigration to Germany: an analysis based on local labor markets," Review of Economics and Statistics, 79(4), 594-604.

Roos, M. W. (2006): "Regional price levels in Germany," Applied Economics, 38(13), 1553-1566.

TUIK (2014): Turkish Regional Statistics. Turkish Statistical Institute: Ankara.

UNCHR (2014): UNCHR Turkey Syrian Refugee Daily Sitreps Dec-2012 and Dec-2013. United Nations High Commissioner for Refugees.

ÖzDen, S. (2013): "Syrian refugees in Turkey," Mpc research report 2013/05. 


\section{Appendix A}

Figure A1: Development of inflation rates

(a) Housing inflation

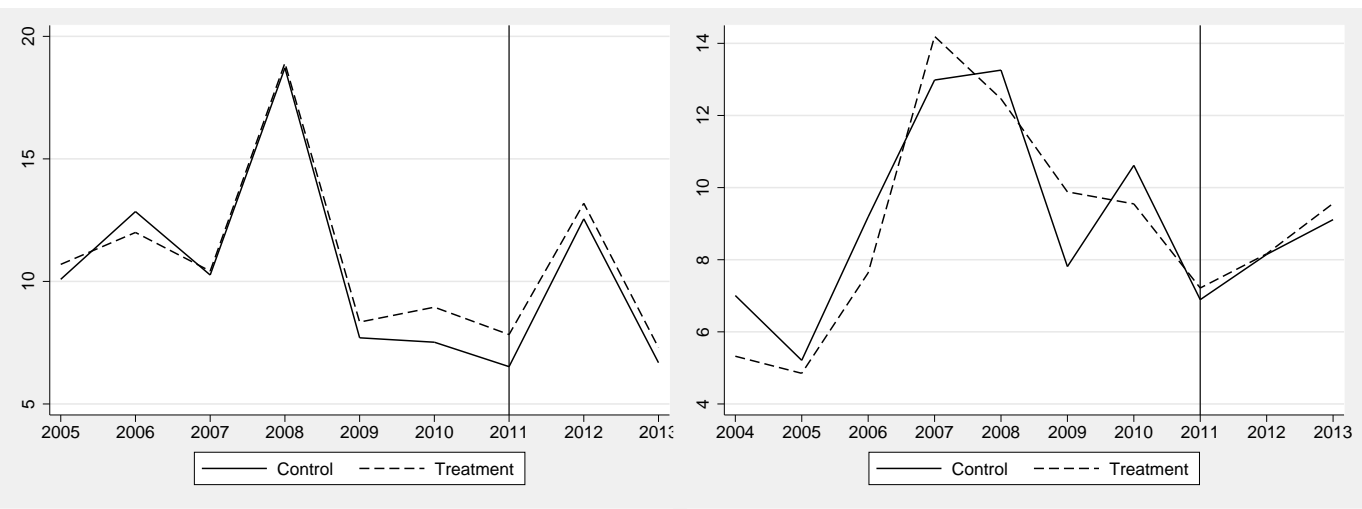

(c) Hospitality inflation

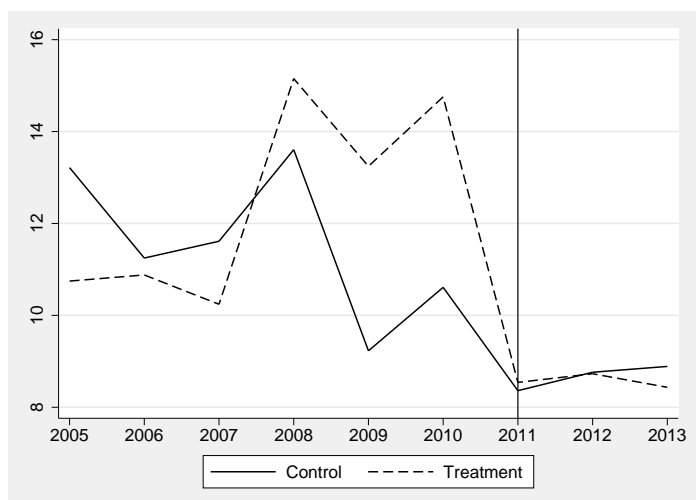


Figure A2: Development of employment rates

(a) High education employment rate

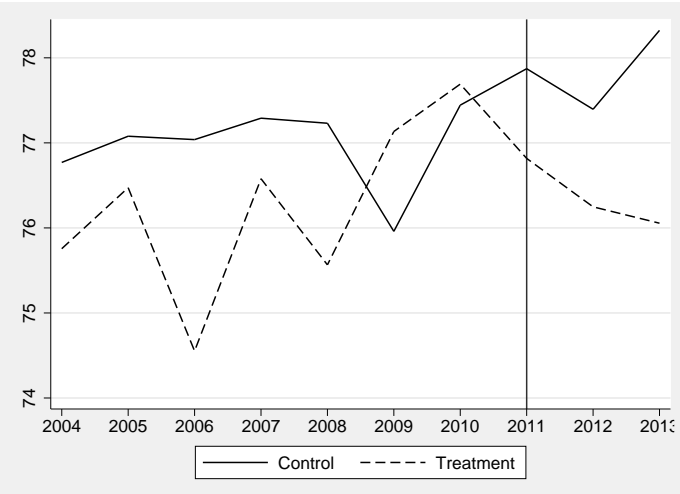

(b) Medium education employment rate

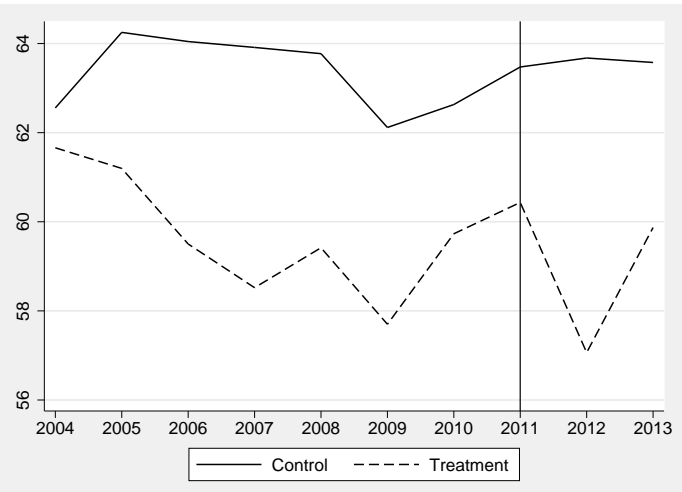

(c) Low education employment rate

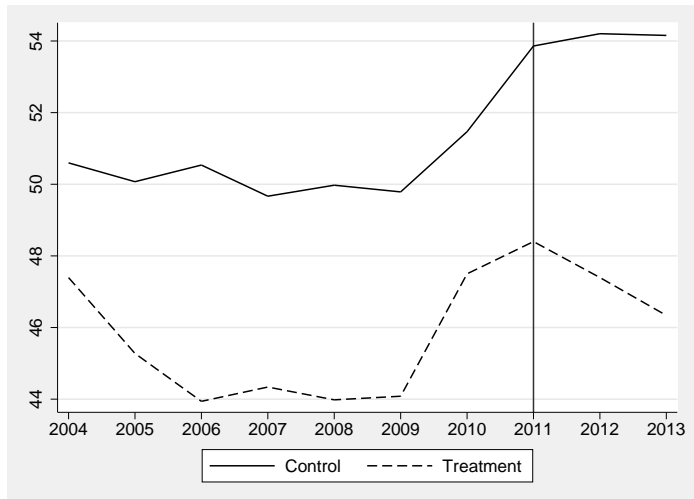


Figure A3: Development of inter-country migration

(a) Number of individuals entering the(b) Number of individuals exiting the province province

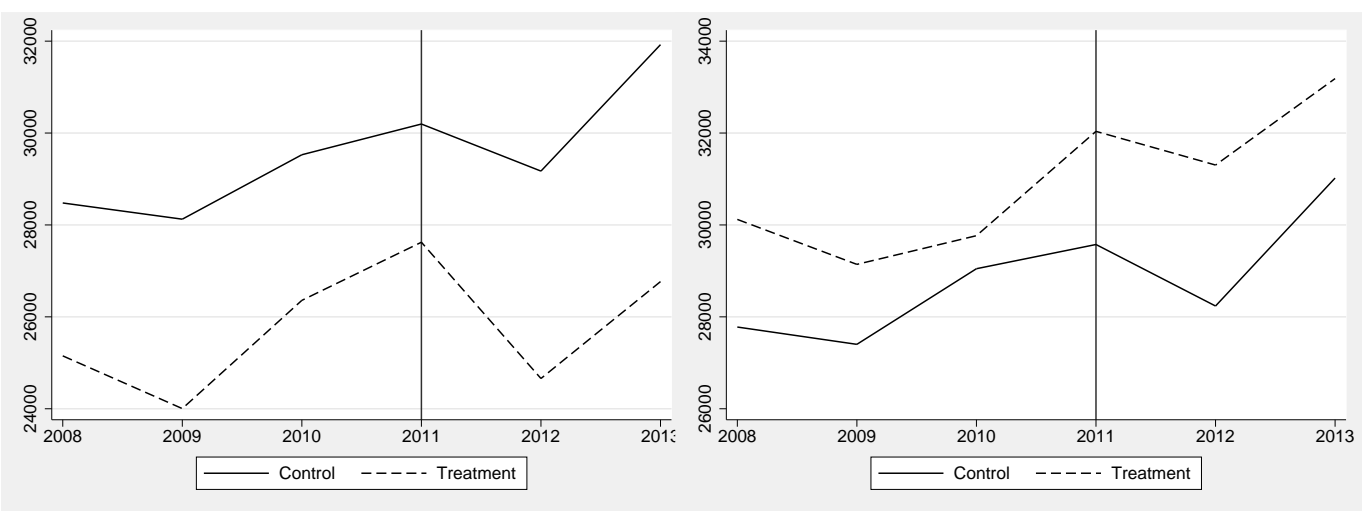

(c) Net migration (Entry-Exit)

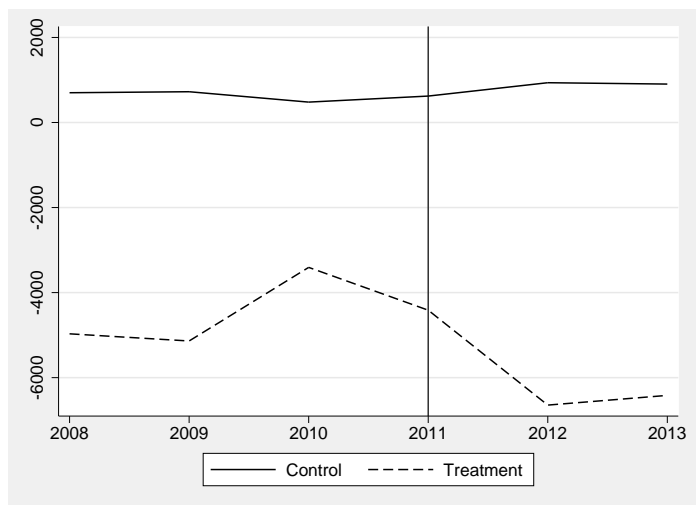

